\title{
Editorial Note: Smart Technologies for Social Good
}

Published online: 1 October 2018

(C) Springer Science+Business Media, LLC, part of Springer Nature 2018

Multimedia Tools and Applications gratefully acknowledges the editorial work of the scholars listed below on the special issue entitled, "Smart Technologies for Social Good."

Of 12 papers submitted to this issue, 6 were eventually accepted after a stringent peerreview process.

\author{
Barbara Guidi (Corresponding Guest Editor) \\ University of Pisa, Pisa, Italy \\ guidi@di.unipi.it \\ Laura Ricci \\ University of Pisa, Pisa, Italy \\ laura.ricci@unipi.it
}

Publisher's Note Springer Nature remains neutral with regard to jurisdictional claims in published maps and institutional affiliations. 